\title{
Misery Loves Company? A Meta-Regression Examining Aggregate Unemployment Rates and the Unemployment- Mortality Association
}

\author{
David J. Roelfs ${ }^{\mathrm{a}}$, Eran Shor ${ }^{\mathrm{b}}$, Aharon Blank ${ }^{\mathrm{b}}$, and Joseph E. Schwartz ${ }^{\mathrm{c}}$ \\ David J. Roelfs: david.roelfs@louisville.edu \\ aDepartment of Sociology; 130 Lutz Hall; University of Louisville; Louisville, KY 40215; USA; \\ $1-502-852-8038$ \\ bDepartment of Sociology; McGill University; Montreal; Quebec H3A 2T7; Canada \\ 'Department of Psychiatry; Stony Brook University; Stony Brook, NY 11794; USA
}

\section{Abstract}

PURPOSE-Individual-level unemployment has been consistently linked to poor health and higher mortality, but some scholars have suggested that the negative effect of job loss may be lower during times and in places where aggregate unemployment rates are high. We review three logics associated with this moderation hypothesis: health selection, social isolation, and unemployment stigma. We then test whether aggregate unemployment rates moderate the individual-level association between unemployment and all-cause mortality.

METHODS-We use 6 meta-regression models (each utilizing a different measure of the aggregate unemployment rate) based on 62 relative all-cause mortality risk estimates from 36 studies (from 15 nations).

RESULTS-We find that the magnitude of the individual-level unemployment-mortality association is approximately the same during periods of high and low aggregate-level unemployment. Model coefficients (exponentiated) were 1.01 for the crude unemployment rate ( $p$ $=0.27), 0.94$ for the change in unemployment rate from the previous year $(p=0.46), 1.01$ for the deviation of the unemployment rate from the 5-year running average $(p=0.87), 1.01$ for the deviation of the unemployment rate from the 10-year running average $(p=0.73), 1.01$ for the deviation of the unemployment rate from the overall average (measured as a continuous variable; $p=0.61$ ), and showed no variation across unemployment levels when the deviation of the unemployment rate from the overall average was measured categorically. Heterogeneity between studies was significant $(p<.001)$, supporting the use of the random effects model.

CONCLUSIONS-We found no strong evidence to suggest that unemployment experiences change when macro-economic conditions change. Efforts to ameliorate the negative social and

(C) 2015 Published by Elsevier Inc.

Publisher's Disclaimer: This is a PDF file of an unedited manuscript that has been accepted for publication. As a service to our customers we are providing this early version of the manuscript. The manuscript will undergo copyediting, typesetting, and review of the resulting proof before it is published in its final citable form. Please note that during the production process errors may be discovered which could affect the content, and all legal disclaimers that apply to the journal pertain. 
economic consequences of unemployment should continue to focus on the individual and should be maintained regardless of periodic changes in macro-economic conditions.

\section{MeSH KEYWORDS}

Unemployment; Mortality; Meta-analysis

\section{INTRODUCTION}

Individual-level unemployment has been consistently linked to poor health and higher mortality [1-5]. However, some scholars have suggested that this relationship may be moderated by the aggregate unemployment rates in a given place. More specifically, scholars have proposed that (when compared to their employed contemporaries) persons who become unemployed when the unemployment rate is high will have a lower relative risk for adverse health outcomes than persons who become unemployed when the unemployment rate is low [see 6,7-15]. In other words, the economic context in which a person becomes unemployed may influence the severity of the effects of being unemployed. Being unemployed during a period when many others are also unemployed may be fundamentally different than becoming unemployed during an economic boom.

Multiple logics have been offered for why we might expect the unemployment-mortality association to weaken when aggregate unemployment is high. First, the unemploymentmortality association might be confounded by health selection factors. During periods when unemployment rates are low, it may be that the people who become unemployed are primarily those with pre-existing health problems. However, when unemployment rates are high, a substantial number of healthy people may also become unemployed. The increased numbers of healthy unemployed persons may consequently push down the mortality rate for the unemployed group as a whole, rendering it closer to the (lower) mortality rate for employed persons.

Second, it may be that levels of social isolation are reduced during hard economic times because there are more unemployed persons around with whom an unemployed person can exchange social support. This mechanism can work in two ways. First, interaction among unemployed persons can arise out of social ties created subsequent to becoming unemployed. For example, a substantial number of unemployed persons use public libraries and employment centers to find employment, particularly among populations with limited home internet access [16]. In these locations, the unemployed have a chance to meet others who share their status. The information sharing and social ties created in this way, temporary and weak as they may be, may help to reduce feelings of isolation and self-blame. The larger pool of people visiting libraries and employment centers during periods of high unemployment may increase the odds of tie initiation and thus potentially offset some of the negative effects of unemployment. Second, interaction among unemployed persons may be based on social connections that existed prior to unemployment. For example, a person who becomes through a mass layoff would have social connections with their former coworkers [13]. Through these connections, workers may be able to frame their unemployment as beyond their control and therefore experience fewer negative psychological effects from 
their unemployment. In a similar fashion, existing residential connections between neighbors make it reasonable to expect that high neighborhood unemployment rates might reduce the negative impacts of individual unemployment [17]. Despite a higher incidence of some types of social problems, higher rates of resource sharing and other similar exchanges of support have indeed been observed in lower income neighborhoods with high unemployment rates [18].

Finally, it may be that the general public becomes more likely to view unemployment as something beyond the individual's control during periods of high unemployment, reducing the stigma (and thus stress) often associated with losing a job. As Clark [7, p. 346] argues, "unemployment always hurts, but it hurts less when there are more unemployed people around." While Martikainen and Valkonen [12] note that it is unlikely that societal attitudes about individual responsibility for becoming unemployed would change over relatively short periods of time, one may expect that if national economic conditions remain bad for an extended period less blame would be placed on unemployed individuals for their plight.

While each of these explanations is feasible, one must note that the mere premise that the unemployment-mortality association weakens when unemployment rates are high is still questionable, and that the search for mechanisms may therefore be premature. In other words, we do not yet have conclusive evidence that aggregate unemployment rates systematically affect the unemployment experience. The purpose of the present study is to test whether the aggregate unemployment rate in a nation is associated with any change in the magnitude of association between mortality and job loss.

Existing research in this area is limited, often confined to the comparison of only two time periods within a single nation, and reported effects are often inconsistent. Some of these studies indeed support the claim that aggregate unemployment rates have an important moderating effect. For example, in a study of working-age Finnish men and women, Martikainen and Valkonen [12] found that those who became unemployed for the first time during a period of low unemployment rates had a higher relative mortality ratio than those who became unemployed for the first time during a period of high unemployment rates. Similarly, in a study of the young working-age population in Australia, Scanlan and Bundy [19] found that the health of unemployed persons was worse during a time of low unemployment. Similar supporting evidence has been reported by Martikainen, Maki, and Janttii [13] and by Henriksson et al. [9]. However, other studies found no effect of the aggregate unemployment rate on the magnitude of the relative risk $[6,10,11,20,21]$.

In the present study, we use meta-regression methods to examine the effect of aggregate unemployment rates on the individual-level association between unemployment and allcause mortality on a cross-national level. Our study follows in the footsteps of another recent study of the unemployment-mortality association [1], which sought to determine the mean level of risk. In this previous study, the authors did not examine the potential moderating effect of national economic conditions. In the present study we seek to fill this lacuna. 


\section{MATERIAL AND METHODS}

The present study is part of a larger effort to examine the associations between various types of negative, stressful life events (e.g., unemployment, divorce/separation, widowhood, war zone exposure, etc.) and all-cause mortality. For the parent study, we identified candidate papers using electronic keyword searches (June 2005 and again in July 2008) using Medline, EMBASE, CINAHL, and Web of Science (see Figure 1; see Section 1 of Appendix for the full search algorithm used for Medline; information on the remaining search algorithms is available from the authors upon request). We identified additional candidate papers through iterative searches of bibliographies and citations. A study was included if the outcome variable was all-cause mortality, the experience of a stressful life event was measured at the individual level (rather than at the neighborhood level), and a clear comparison was made between a group of people who experienced a particular stressful event and another group who did not (see Section 2 of Appendix for details regarding coding procedures and variables for which data were sought). No restrictions were placed on the year a study was published, in what language it was originally written, or the type of outlet in which the paper appeared. In all, we examined 729 studies in detail (see Figure 1). Of these, 262 contained data that could be coded into the parent study database and selected from for the examination of particular stressful live events such as unemployment.

Of the 262 studies in the parent database, 42 examined the association of unemployment with all-cause mortality. We excluded six of these 42 because they contained redundant data. The analysis presented below is thus based on 62 relative mortality risk estimates from 36 studies (see forest plot in Figure 2) obtained from samples of the working-age population (ages 15-65). Multiple relative risk estimates were taken from a single study/data source solely when they were based on non-overlapping sub-samples (i.e., represent independent risk estimates). Statistical methods varied from study to study, necessitating the conversion of all non-hazard-ratio point estimates into hazard ratio format (the most frequently reported type; see Section 3 of Appendix). In cases where the death rate information required for this conversion was not available in the published study (19 of the 62 risk estimates), we calculated the death rate (matched by nation, age, and year) using information from the Human Mortality Database [53] and (for the case of Costa Rica) the World Health Organization's Department of Health Statistics and Informatics [54].

Study quality was assessed using the Newcastle-Ottawa scale for nonrandomized trials [55]. Analyses were conducted in STATA using version 1.3 of the "robumeta" package provided by Fisher and Tipton [see 56]. The possibility of selection and publication bias was examined using a funnel plot of the log hazard ratios (HR) against sample size, Egger's test [57], and Peters' test $[58,59] . Q$-tests and examinations of the unexplained heterogeneity variance component were used to assess the presence and magnitude of heterogeneity in the data.

We test whether the aggregate unemployment rate moderates the unemployment-mortality association using a random effects meta-regression model with robust standard errors (to account for possible intra-study correlations between effect sizes; we assumed an intra-study effect size correlation of $\rho=.80$ ). We used the $\log$ of the hazard ratio (unemployed vs. 
employed) as the dependent variable. When the resulting regression coefficients are exponentiated, the results take the form of a comparison of the magnitudes of the hazard ratios under varying study conditions.

The inverse of the variance of the log-hazard was used as the weighting variable. When variances or standard errors were not directly reported, they were calculated using (1) confidence intervals, (2) $t$ statistics, (3) $\chi^{2}$ statistics, or (4) $p$-values. When upper-limit $p$ values were the only estimate of statistical significance available (e.g. in cases where we knew only that the $p$-value lay somewhere between 0.01 and 0.05 ), the midpoint of the upper and lower limits was used to estimate the $p$-value. For 3 of the 62 relative mortality estimates no standard error was available from which to calculate the inverse variance weight. For these three cases, the standard error was estimated using multiple regression (with predictor variables selected based solely on whether or not a variable had few/no missing values). Significant predictors of the standard error were sample size (log transformed), mean age at baseline, follow-up duration, the magnitude of the hazard ratio, and publication date (Multiple $R=.72$ ). The mortality measure used was all-cause mortality.

Our focal independent variable was the national unemployment rate at time $t$ (baseline year), a measure of the business cycle conditions (and hence labor demand) present within a given nation at a given time. To ensure robust results, we calculated six alternative specifications for use in separate models. The most basic model used the crude unemployment rate. Because people likely assess their own situation by making comparisons with localized conditions from the recent past, we examined various aggregate unemployment measures meant to capture how individuals would have perceived their own unemployment context. Specifically, we calculated the change in unemployment rate from the previous year, the deviation of the unemployment rate from the 5-year running average, and the deviation of the unemployment rate from the 10-year running average.

In addition, we calculated the deviation of the unemployment rate from the overall average. The advantage of making comparisons to the overall average is that we can assess whether or not unemployment was objectively high or low in a given place and time. We argue that this operationalization of relative unemployment most directly corresponds to those used by previous examinations of this hypothesis [see again 6,7-15]. Finally, we calculated dummy variables based on the quartiles for the deviation of the unemployment rate from the overall average. The use of a categorical specification for the unemployment rate, rather than treating the relative unemployment rate only as a continuous variable, helps to examine whether a non-linear effect might be present. This allows us to examine the possibility suggested in some recent studies that the unemployment-health association only fundamentally changes during economic crises $[60,61]$.

We collected data on the national unemployment rate in the civilian population aged 15 or greater primarily from Organization for Economic Cooperation and Development (OECD) reports, with supplemental data obtained from the World Bank, the International Monetary Fund (IMF), the International Labor Organization (ILO), and the national statistical bureaus of Israel and Taiwan. Comparable data on the aggregate unemployment rate were available between 1960-2004 for Belgium, Denmark, Finland, Italy, New Zealand, Switzerland, and 
the United States; 1961-2004 for Japan and the United Kingdom; 1963-2004 for Sweden; 1964-2004 for Australia and Spain; 1978-2008 for Taiwan; 1984-2004 for Israel; and 1985-2004 for Costa Rica. Aggregate unemployment rates were matched to mortality risk estimates according to the baseline year in which data collection began, the country in which the study was conducted, and both the age distribution and the gender distribution of the sample being studied.

Other control variables in the meta-regression models were included based on both data availability and theoretical importance. They included: (1) the proportion of respondents who were male (to control for gender differences in the mortality risk associated with unemployment); (2) the mean age of sample at baseline (to control for age differences in the underlying death rate); (3) the age of the study (i.e. years elapsed since the beginning of baseline; included to control for unmeasured changes in research methodology), divided by 10 ; (4) the time elapsed between the end of baseline and the beginning of follow-up; (5) the maximum follow-up duration; (6) the type of comparison group (to control for differences caused by comparing to employed persons only vs. the general population); (7) whether unemployment included students, early retirees, etc. (included to control for differences caused by including anyone other than the involuntarily unemployed in the numerator group); (8) the geographic region in which the study was conducted (to roughly control for differences in behavioral norms and government policies at the nation-state level); (9) a series of variables indicating whether studies controlled for sex, age, socioeconomic status, and health (to examine differences between studies that reduced confounding by including key control variables vs. those that did not); (10) the study's sample size, log transformed (to control for any selection bias present in the data); (11) whether the standard error was estimated (yes or no; an indicator variable was created so analyses could be conducted both with and without data points where the standard error was estimated); and (12) the Newcastle-Ottawa Scale rating (range, 0-9; included to control for differences in study quality).

The series of indicator variables with respect to whether a study controlled for sex, age, socioeconomic status, or health (number 9 in the list above) is particularly important, given what is known about the possibility of selection effects. For example, if health selection is at work, then one would expect those who become unemployed to already be less health than those who retain their jobs. In addition, health selection is likely to be particularly strong during periods of healthy economic growth but less strong when unemployment is high. Either way, if selection effects are at work, one would expect the observed unemploymentmortality association to be weaker (or non-existent) in studies that control for health when compared to studies that do not. The indicator variable for whether a study controlled for health provides a test of this selection hypothesis. Socioeconomic selection effects, age selection effects, and sex selection effects are likewise tested through their corresponding indicator variables.

\section{RESULTS}

In Table 1 we report descriptive statistics for the 62 hazard ratios (HRs) included in the analysis. Among all nations and years, the aggregate unemployment rate ranged from $0.7 \%$ 
(Denmark in 1970) to $29.6 \%$ (Spain in 1996), with an overall average of 6.6\%. All but 11 of the 62 aggregate unemployment rates were below $10 \%$, and only 5 were above $15 \%$. Neither the lowest nor the highest aggregate unemployment rates appeared to be associated with any single nation or region. When examined relative to the within-nation average unemployment rate, the deviation of the unemployment rate ranged from 4.81 percentage points below the mean to 13.80 points above the mean. We refer the reader to Table 1 for the descriptive statistics on the control variables used in the analysis.

The mean HR across all studies in the analysis was 1.62 (95\% confidence interval, 1.451.80 ), indicating that the mortality risk for unemployed persons was $62 \%$ higher, on average, than the mortality risk for employed persons. Caution must be used when interpreting this result, however, because it does not take into account any of the substantial heterogeneity between studies. In Table 2 we report exponentiated regression coefficients from six metaregression models, with each exponentiated coefficient representing a ratio comparison of two HRs. For example, the exponentiated coefficient corresponding to the Scandinavian region represents the ratio of the mean HR for Scandinavia to the mean HR for the comparison group of nations. Among the continuous measures of the unemployment rate (Models 1 through 5), neither the crude unemployment rate $(p=0.27)$, the change in unemployment rate from the previous year $(p=0.46)$, the deviation from the 5 -year running average ( $p=0.87)$, the deviation from the 10-year running average $(p=0.73)$, nor the deviation from the overall average $(p=0.61)$ were significant predictors of HR magnitude. In addition, we found no significant effect when we used a categorical measure of the deviation from the overall average (based on quartiles; Model 6). Put together, our findings do not support the hypothesis that the individual unemployment-mortality relationship is moderated by the aggregate unemployment rate.

Across the 6 models, there was a consistently significant difference in HR magnitude associated with differences in the gender composition. Studies examining only men reported HRs that ranged from $35 \%$ to $39 \%$ higher than studies examining only women. The mean age of the study sample was also a significant predictor. Although no difference was found in the mean HR between studies with a mean age less than 40 (reference group) and studies with a mean age from 40-49.9, studies with a mean age from 50-65 had HRs that ranged from $29 \%$ to $31 \%$ lower than the reference age group. Studies comparing unemployed persons to the general population had HRs that ranged from $41 \%$ to $51 \%$ lower than studies that made comparisons directly to employed persons.

The mean HR ranged from $32 \%$ to $36 \%$ lower among studies that controlled for health behaviors such as smoking and drinking, when compared to studies that did not control for these factors. This suggests that health selection is very much effecting the unemploymentmortality association. It is important to note, however, that some level of association remains even after health selection is taken into account. Thus, it remains valid to talk of a direct unemployment-mortality linkage.

Non-significant predictors included the age of the study; the measures of follow-up structure and duration; whether a study included the voluntarily unemployed and/or disabled persons with involuntarily unemployed persons; the region where the study was conducted; whether 
a study controlled for sex, age, and/or socioeconomic status; the sample size of the study (logged); whether an estimated standard error was used to calculate the inverse variance weight; and the measure of study quality.

\section{Robustness checks}

Cochrane's $Q$-test for data heterogeneity indicated low levels of residual heterogeneity in the model. Yet, random-effects models remained necessary in order to manage unobserved sources of heterogeneity (as indicated by the significant association between sample size and HR magnitude and by the significance of the unexplained heterogeneity variance component). Some sampling variability was visible in the funnel plot of the log hazard ratios versus sample size (see Figure 3) and funnel plot asymmetry was confirmed using Eggers' test $(p<0.001)$. However, Peters' test for funnel plot asymmetry in heterogeneous data showed that heterogeneity was not likely a major problem in the final analyses $(p=0.41)$.

We checked the robustness of the model to variable over-specification. It is normal in regression to limit the ratio of cases to independent variables (norms vary, but a maximum of between 5 and 10 cases per independent variables is common). With 62 cases in the analysis, this would imply a limit of between 6 to 12 independent variables. The results shown in models 1 through 6, however, are based on 19 independent variables. We therefore ran a two-stage parsimonious model (results not shown in table) in order to compare our reported results against a model with fewer variables. We first identified a parsimonious set of covariates (examining all variables except for those measuring unemployment rate) using forward selection ( $p<.10$ to enter). Next, we sequentially examined each unemployment rate measure. None of the unemployment measures were significant at the $p<.10$ level. The significant covariates in the parsimonious model were the proportion of the sample that was male, the mean age of the study sample at baseline, the indicator for whether the comparison group was the general population, the indicator for whether the unemployed group included those not in the labor force, the indicator for whether a study controlled for health behaviors, and the sample size of the study (logged). Both the pattern of significance and the magnitudes of the regression coefficients was consistent with the results shown in Table 2.

\section{DISCUSSION}

Our study offered the first large-scale cross-national test for the hypothesis that unemployment may be relatively less harmful during periods of high unemployment rates. Our findings do not provide support for this hypothesis. We tested six alternative specifications for the unemployment rate (continuous and categorical) and none of them was statistically significant at a $p$-value below 0.05 ( $p$-values ranged from 0.27 to 0.97 ).

In Model 1 (Table 2) we examined the potential effect of the crude unemployment rate. Because most of the variation in unemployment rates is between nations, rather than between years within nations, the results from this model do not tell us much about the within-nation effect. They do show, however, no evidence that the individual-level unemployment-mortality association differs between countries. This is remarkable given the large differences between the aggregate unemployment rates of the countries included in the analysis (ranging from $0.7 \%$ in Denmark in 1970 to $29.6 \%$ in Spain in 1996). This finding is 
consistent with studies that have found no relationship between subjective well-being and other aspects of the economic support structure of nations [see 62]. Caution must be used when interpreting the result from Model 1, however, because it reflects both between and within nation variability. A more conservative interpretation would be that the crude unemployment rate fails to significantly account for the combination of these two aspects of data heterogeneity.

However, one might argue cross-national comparisons are not the right ones. That is because people are probably less likely to make comparisons with people in other nations and more likely to make comparisons with localized conditions from the recent past. In Models 2 through 4 , we examined various aggregate unemployment measures meant to capture how individuals would have perceived their own unemployment context. This included (1) the change in unemployment rate from the previous year; (2) the deviation of the unemployment rate from the 5-year running average; and (3) the deviation of the unemployment rate from the 10-year running average. For each model, change and deviation scores were calculated on a nation-by-nation basis. Each of these three alternative specifications depends only on economic information that would have been available to study subjects and each alternative specification focuses only on within-nation variations in the unemployment context.

Therefore, the coefficients for the unemployment rate variables represent very direct tests of the central hypothesis examined in this paper. The relative unemployment rate measures for all three models were not significant at the 0.10 level (the lowest $p$-value of any of the alternate measures in models 2 through 4 was $p=0.46$ ). The fact that none of these alternative within-nation measures was significant suggests that unemployed persons assess their situation from a very personal vantage point, giving little consideration to broader group and societal trends. This too is consistent with existing psychological research on the perception of unemployment. For example, Walker and Mann [63] showed that levels of stress related to unemployment were explained primarily by the gap between people's personal expectations and their actual attainment, rather than by the relative standing of the group(s) to which they belonged.

In Model 5, we examined aggregate unemployment measures relative to the overall average unemployment rate in each nation (1960-2004 for Belgium, Denmark, Finland, Italy, New Zealand, Switzerland, and the United States; 1961-2004 for Japan and the United Kingdom; 1963-2004 for Sweden; 1964-2004 for Australia and Spain; 1978-2008 for Taiwan; 19842004 for Israel; and 1985-2004 for Costa Rica). As such, we calculated deviation scores using information that was not necessarily available to the individuals in the original studies (i.e., using past, present, and future unemployment rates). The advantage of making comparisons to the overall averages, again, is that we can assess whether or not unemployment was objectively high or low in a given place and time. Once again, the relative unemployment rate was not significant.

Finally, in Model 6, we further examined the potential effect of aggregate unemployment rates relative to overall averages. As indicated earlier, the categories for the relative unemployment rate were defined by quartile and used to determine whether a non-linear effect might be present. No single quartile emerged as significantly different from the lowest quartile, and there was also no significant pattern in the coefficients (linear or otherwise). 
The lack of a significant difference, even for the highest quartile of unemployment rates, indicates a lack of support for the hypothesis that the unemployment-mortality association will differ if an economic crisis is happening.

Taken altogether, none of our various attempts to operationalize aggregate unemployment yielded a significant result. In other words, our extensive cross-national and cross-period analyses lend no support to the premise that aggregate unemployment rates moderate the relationship between individual unemployment and mortality. The various theoretical explanations suggested for such a moderation effect therefore seem premature.

\section{Limitations}

We cannot rule out the possibility that aggregate unemployment rates remain an important moderator with respect to outcomes other than all-cause mortality. Indeed, recent research endeavors reported evidence of a moderating effect for outcomes such as suicide [64] and self-rated health [19]. Still, we should note that the existence and direction of the moderation effect in these cases remains somewhat questionable. While some studies have found that self-rated health is worse (rather than better) among the unemployed when aggregate unemployment rates are high [65], others have found that both the short-term unemployed and those who remain employed report worse health during recessions [15]. In addition, similarly to the present study, some studies have found no relationship between unemployment rates and self-reported health $[14,66]$. Moreover, our results suggest that any moderating effect for aggregate unemployment rates for these "lower level" health outcomes does not necessarily translate into a moderating relationship with respect to more severe health outcomes such as mortality.

We must also point out that the national unemployment rate is a more appropriate measure of macro-economic conditions for some studies than for others. Many of the studies used in the analysis gathered data from a nationally representative sample; for these the national unemployment measures are directly applicable. For a subset of studies, however, the geographic area examined was more restricted. National unemployment data in these instances is only a proxy measure of local economic conditions. To the extent that conditions in a particular locality are decoupled from national conditions, the results would fail to fully test this paper's main hypothesis. Furthermore, research has suggested that people are more likely to be affected by unemployment in their local area rather than the nation as a whole and that national unemployment statistics sometime mask important regional variations [17].

Relatedly, an assumption underlying the study design is that the key difference between time periods is the unemployment level, and that the unemployment rate is therefore the only key moderator to be accounted for when examining the individual-level unemploymentmortality association. This is unlikely to be true. A multitude of other factors may also differ between time periods, including changes in medical treatments and technologies, highway safety, and social welfare systems. The inclusion of study age as a control variable helps to account for linear trends in unobserved factors, but this is not the ideal approach. Including fixed effects based on time would be the preferred method. Unfortunately, the limited number of studies precludes the use of this method. 
Our meta-regression model was also limited by the follow-up durations of the original studies. While we found that the aggregate unemployment rate was not associated with HR magnitude, this lack of association may derive partly from the fact that the majority of our relative risk estimates were from studies with follow-up durations of greater than 5 years. Assuming that the individual-level effects of unemployment and mortality are largely concentrated in the period immediately following the loss of employment, data derived solely from studies with short follow-up durations may have produced different results with respect to the aggregate-level unemployment measure. Specifically, if the negative effects of unemployment are transitory, then the power to detect this transitory effect decreases as the follow-up period increases. However, in both our current and previous analyses [1] we showed that follow-up duration was not a significant predictor of the magnitude of association between unemployment and mortality, suggesting that the effect of becoming unemployed persists into later years.

One must also keep in mind that data limitations prevented us from looking for differences based on the number of times a person has been employed or for differences based on the duration of unemployment. From a psychological perspective, one might expect the reactions of a person who becomes unemployed for the first time to differ substantially from a person who has experienced repeated unemployment. From a social perspective, one might also expect differences in how these two opposite types of unemployed persons might be treated by others (including prospective employers). Relatedly, the lack of life-course information with respect to the actual duration of unemployment did not allow us to measure the unemployment rate over a time period rather than a single point in time. Our choice to use the unemployment rate in the year a study's baseline data collection began as a measure of the macro-economic conditions is thus only an approximation (though we would argue the only method available).

The limitations discussed in the previous study on this dataset [1], most of which are common issues with meta-regression analysis, are also applicable to the present study. In brief, there is an unknown degree of non-reporting in the literature, we cannot completely rule out the presence of selection bias, the studies included in the meta-regression are observational, and there remains the possibility that selection effects account for some portion of the observed unemployment-mortality association. There is some evidence for health selection specifically, as Models 1 through 6 in Table 2 show that studies that controlled for health behaviors reported HRs that were between 34\% to 36\% lower than studies that did not control for health behaviors.

\section{Conclusions}

In the introduction to the paper, we argued that the search for explanations as to why we might expect the unemployment-mortality association to weaken when aggregate unemployment rates are high may be premature, as research had yet to robustly establish whether or not aggregate unemployment rates systematically affected individual-level associations. Using 6 separate meta-regression models, we found no strong evidence that the aggregate unemployment rate modified the direction or magnitude of the individual-level unemployment-mortality association. The overall impression of these results is that efforts 
to ameliorate the negative social and economic consequences of unemployment should continue to focus on the individual and should be maintained regardless of periodic changes in macro-economic conditions.

While we found that the aggregate unemployment rate does not affect the unemployment experience, it remains plausible that a mediating effect for mass unemployment still exists when the group of unemployed people already shares some social connection with one another. For example, one might reasonably expect that a person who is unemployed along with many others from the same workplace (e.g., a mass layoff) would have a difference experience than a person who is unemployed alone. This is, in fact, one of the secondary findings of Martikainen, Maki, and Jantti [13]. This type of hypothesis is also consistent with the literature on posttraumatic stress, which has found that experience trauma in a group is less harmful than experiencing it alone. In a similar fashion, existing residential connections between neighbors make it reasonable to expect that high neighborhood unemployment rates might reduce the negative impacts of individual unemployment as well, as suggested by Milner et al. [17]. The current study primarily examines unemployment in contexts where inter-personal connections are unlikely. In order to fully understand the effect of unemployment levels on the unemployment experience, more research is needed at the workplace and neighborhood level.

\title{
Acknowledgments
}

The authors are grateful for the support provided by grant HL-76857 from the National Institutes of Health. The funding source had no involvement in the collection, analysis and interpretation of the data, in the writing of the report, and in the decision to submit the paper for publication.

\section{ABBREVIATIONS}

\author{
HR Hazard Ratio \\ OECD Organization for Economic Cooperation and Development \\ IMF International Monetary Fund \\ ILO International Labor Organization
}

\section{References}

1. Roelfs DJ, Shor E, Davidson KW, Schwartz JE. Losing Life and Livelihood: A Systematic Review and Meta-Analysis of Unemployment and All-Cause Mortality. Social Science \& Medicine. 2011; 72(6):840-54. [PubMed: 21330027]

2. Osthus S. Health effects of downsizing survival and job loss in Norway. Social Science \& Medicine. 2012; 75(5):946-53. [PubMed: 22682662]

3. McLeod CB, Lavis JN, MacNab YC, Hertzman C. Unemployment and Mortality: A Comparative Study of Germany and the United States. American Journal of Public Health. 2012; 102(8):154250. [PubMed: 22698036]

4. Nishikitani M, Tsurugano S, Inoue M, Yano E. Effect of unequal employment status on workers' health: Results from a Japanese national survey. Social Science \& Medicine. 2012; 75(3):439-51. [PubMed: 22357298] 
5. Garcy AM, Vagero D. The length of unemployment predicts mortality, differently in men and women, and by cause of death: A six year mortality follow-up of the Swedish 1992-1996 recession. Social Science \& Medicine. 2012; 74(12):1911-20. [PubMed: 22465382]

6. Ahs AMH, Westerling R. Mortality in Relation to Employment Status during Different Levels of Unemployment. Scandinavian Journal of Public Health. 2006; 34(2):159-67. [PubMed: 16581708]

7. Clark AE. Unemployment as a Social Norm: Psychological Evidence from Panel Data. Journal of Labor Economics. 2003; 21(2):323-51.

8. Corcoran P, Arensman E. Suicide and employment status during Ireland's Celtic Tiger economy. European Journal of Public Health. 2011; 21(2):209-14. [PubMed: 20110275]

9. Henriksson KM, Lindblad U, Agren B, Nilsson-Ehle P, Rastam L. Associations Between Unemployment and Cardiovascular Risk Factors Varies with the Unemployment Rate: The Cardiovascular Risk Factor Study in Southern Sweden (CRISS). Scandinavian Journal of Public Health. 2003; 31(4):305-11. [PubMed: 15099037]

10. Iversen L, Andersen O, Andersen PK, Christoffersen K, Keiding N. Unemployment and Mortality in Denmark, 1970-80. British Medical Journal. 1987; 295(6603):879-84. [PubMed: 3119084]

11. Lundberg O, Diderichsen F, Yngwe MA. Changing health inequalities in a changing society? Sweden in the mid-1980s and mid-1990s. Scandinavian Journal of Public Health. 2001; 29(Supplement 55):31-9. [PubMed: 11482794]

12. Martikainen PT, Valkonen T. Excess Mortality of Unemployed Men and Women during a Period of Rapidly Increasing Unemployment. Lancet. 1996; 348(9032):909-12. [PubMed: 8843808]

13. Martikainen PT, Maki N, Jantti M. The Effects of Unemployment on Mortality Following Workplace Downsizing and Workplace Closure: A Register-Based Follow-up Study of Finnish Men and Women during Economic Boom and Recession. American Journal of Epidemiology. 2007; 165(9):1070-5. [PubMed: 17363363]

14. Novo M, Hammarstrom A, Janlert U. Health hazards of unemployment - only a boom phenomenon? A study of young men and women during times of prosperity and times of recession. Public Health. 2000; 114(1):25-9. [PubMed: 10787022]

15. Novo M, Hammarstrom A, Janlert U. Do High Levels of Unemployment Influence the Health of Those Who Are Not Unemployed? A Gendered Comparison of Young Men and Women During Boom and Recession. Social Science and Medicine. 2001; 53(3):293-303. [PubMed: 11439814]

16. Hoffman, J.; Bertot, JC.; Davis, DM. [accessed 10.24.12] Libraries Connect Communities: Public Library Funding \& Technology Access Study 2011-2012. 2012. http://viewer.zmags.com/ publication/4673a369

17. Milner A, Kavanagh A, Krnjacki L, Bentley R, LaMontagne AD. Area-Level Unemployment and Perceived Job Insecurity: Evidence from a Longitudinal Survey Conducted in the Australian Working-Age Population. Annals of Occupational Hygiene. 2014; 58(2):171-81. [PubMed: 24371046]

18. Haider SJ, McGarry K. Recent Trends in Resource Sharing among the Poor. National Bureau of Economic Research. 2005 NBER Working Paper No. 11612.

19. Scanlan JN, Bundy AC. Is the health of young unemployed Australians worse in times of low unemployment? Australian and New Zealand Journal of Public Health. 2009; 33(1):79-82. [PubMed: 19236364]

20. Moser KA, Goldblatt PO, Fox AJ, Jones DR. Unemployment and Mortality: Comparison of the 1971 and 1981 Longitudinal Study Census Samples. British Medical Journal. 1987; 294(6564):8690. [PubMed: 3105667]

21. Moser KA, Fox AJ, Jones DR, Goldblatt PO. Unemployment and Mortality: Further Evidence from the OPCS Longitudinal Study 1971-81. The Lancet. 1986; 15:365-7.

22. Anson J. The Migrant Mortality Advantage: A 70 Month Follow-up of the Brussels Population. European Journal of Population-Revue Europeenne De Demographie. 2004; 20(3):191-218.

23. Blakely T, Atkinson J, Ivory V, Collings S, Wilton J, Howden-Chapman P. No Association of Neighbourhood Volunteerism with Mortality in New Zealand: A National Multilevel Cohort Study. International Journal of Epidemiology. 2006; 35(4):981-9. [PubMed: 16931531]

24. Costa G, Segnan N. Unemployment and Mortality. British Medical Journal. 1987; 294(June): 1550-1. [PubMed: 3111631] 
25. Farmer IP, Meyer PS, Ramsey DJ, Goff DC, Wear ML, Labarthe DR, et al. Higher Levels of Social Support Predict Greater Survival Following Acute Myocardial Infarction: The Corpus Christi Heart Project. Behavioral Medicine. 1996; 22(2):59-66. [PubMed: 8879457]

26. Gardner J, Oswald A. How is Mortality Affected by Money, Marriage, and Stress? Journal of Health Economics. 2004; 23(6):1181-207. [PubMed: 15556242]

27. Gerdtham U-G, Johannesson M. A Note on the Effect of Unemployment on Mortality. Journal of Health Economics. 2003; 22(3):505-18. [PubMed: 12683964]

28. Gognalons-Nicolet M, Derriennic F, Monfort C, Cassou B. Social Prognostic Factors of Mortality in a Random Cohort of Geneva Subjects Followed Up for a Period of 12 Years. Journal of Epidemiology and Community Health. 1999; 53(3):138-43. [PubMed: 10396489]

29. Helweg-Larsen M, Kjoller M, Thoning H. Do Age and Social Relations Moderate the Relationship between Self-rated Health and Mortality among Adult Danes? Social Science \& Medicine. 2003; 57(7):1237-47. [PubMed: 12899907]

30. Herring AA, Bonilla-Carrión RE, Borland RM, Hill KH. Differential Mortality Patterns Between Nicaraguan Immigrants and Native-born Residents of Costa Rica. Journal of Immigrant and Minority Health. 2010; 12(1):33-42. [PubMed: 18264763]

31. Hirokawa K, Tsutusmi A, Kayaba K. Impacts of Educational Level and Employment Status on Mortality for Japanese Women and Men: The Jichi Medical School Cohort Study. European Journal of Epidemiology. 2006; 21:641-51. [PubMed: 17048083]

32. Jenkinson CM, Madeley RJ, Mitchell JRA, Turner ID. The Influence of Psychosocial Factors on Survival after Myocardial Infarction. Public Health. 1993; 107(5):305-17. [PubMed: 8248465]

33. Johnson JE, Finney JW, Moos RH. Predictors of 5-Year Mortality Following Inpatient/Residential Group Treatment for Substance Use Disorders. Addictive Behaviors. 2005; 30(7):1300-16. [PubMed: 16022928]

34. Kivimaki M, Vahtera J, Virtanen M, Elovainio M, Pentti J, Ferrie JE. Temporary Employment and Risk of Overall and Cause-Specific Mortality. American Journal of Epidemiology. 2003; 158:6638. [PubMed: 14507602]

35. Lavis JN. Unemployment and Mortality: A Longitudinal Study in the United States, 1968-1992. McMaster University Centre for Health Economics and Policy Analysis Working Paper Series. 1998 Working Paper no. 98-5.

36. Manor O, Eisenbach Z, Israeli A, Friedlander Y. Mortality Differentials among Women: The Israel Longitudinal Mortality Study. Social Science \& Medicine. 2000; 51(8):1175-88. [PubMed: 11037208]

37. Manor O, Eisenbach Z, Peritz E, Friedlander Y. Mortality Differentials among Israeli Men. American Journal of Public Health. 1999; 89(12):1807-13. [PubMed: 10589307]

38. Martikainen PT. Unemployment and Mortality among Finnish Men 1981-85. British Medical Journal. 1990; 301(6749):407-11. [PubMed: 2282395]

39. Masudomi I, Isse K, Uchiyama M, Watanabe H. Self-Help Groups Reduce Mortality Risk: A 5Year Follow-up Study of Alcoholics in the Tokyo Metropolitan Area. Psychiatry and Clinical Neurosciences. 2004; 58(5):551-7. [PubMed: 15482588]

40. Morrell S, Taylor R, Quine S, Kerr C, Western J. A Case-Control Study of Employment Status and Mortality in a Cohort of Australian Youth. Social Science \& Medicine. 1999; 49:383-92. [PubMed: 10414822]

41. Morris JK, Cook DG, Shaper AG. Loss of Employment and Mortality. British Medical Journal. 1994; 308:1135-9. [PubMed: 8173455]

42. Moser KA, Fox AJ, Jones DR. Unemployment and Mortality in the OPCS Longitudinal Study. The Lancet. 1984; 324(8415):1324-9.

43. Orth-Gomer, K.; Johnson, JV.; Unden, A-L.; Edwards, M-E. Social Interaction and Mortality in Sweden. Findings in the Normal Population and in Cardiovascular Patients. In: Isacsson, S-O.; Janzon, L., editors. Social Support - Health and Disease Sixth International Berzelius Symposium. Stockholm: Almqvist \& Wiksell International; 1986. p. 21-31.

44. Palloni A, Arias E. Paradox Lost: Explaining the Hispanic Adult Mortality Advantage. Demography. 2004; 41(3):385-415. [PubMed: 15461007] 
45. Regidor E, Calle ME, Dominguez V, Navarro P. Mortality by Social and Economic Characteristics: The Mortality Study of the Autonomous Community of Madrid, Spain. Medicina Clinica (Barcelona). 2001; 116(19):726-31.

46. Robinson N, Lloyd CE, Stevens LK. Social Deprivation and Mortality in Adults with Diabetes Mellitus. Diabetic Medicine. 1998; 15:205-12. [PubMed: 9545121]

47. Sorlie PD, Backlund E, Keller JB. U.S. Mortality by Economic, Demographic, and Social Characteristics - The National Longitudinal Mortality Study. American Journal of Public Health. 1995; 85(7):949-56. [PubMed: 7604919]

48. Spence, NJ. Reproductive Patterns and Women's Later Life Health. Tallahassee: Florida State University; 2006.

49. Stefansson C-G. Long-Term Unemployment and Mortality in Sweden, 1980-1986. Social Science \& Medicine. 1991; 32(4):419-23. [PubMed: 2024157]

50. Tsai SL, Lan CF, Lee CH, Huang N, Chou YJ. Involuntary Unemployment and Mortality in Taiwan. Journal of the Formosan Medical Association. 2004; 103:900-7. [PubMed: 15624038]

51. Voss M, Nylen L, Floderus B, Diderichsen F, Terry PD. Unemployment and Early Cause-Specific Mortality: A Study Based on the Swedish Twin Registry. American Journal of Public Health. 2004; 94:2155-61. [PubMed: 15569968]

52. Weitoft GR, Haglund B, Rosen M. Mortality among Lone Mothers in Sweden: A Population Study. The Lancet. 2000; 355(9211):1215-9.

53. University of California-Berkeley. [accessed 4.26.11] Max Planck Institute for Demographic Research. Human Mortality Database. 2011. http://www.mortality.org

54. World Health Organization. [accessed 4.26.11] Department of Health Statistics and Informatics. WHO Mortality Data base. Mar 25. 2011 http://www.who.int/whosis/mort/download/en/ index.html

55. Wells, GA.; Shea, B.; O’Connell, D.; Peterson, J.; Welch, V.; Losos, M., et al. [accessed 6.01.10] The Newcastle-Ottawa Scale (NOS) for Assessing the Quality of Nonrandomized Studies in Metaanalysis. 2009. http://www.ohri.ca/programs/clinical_epidemiology/nosgen.pdf

56. Tanner-Smith EE, Tipton E. Robust variance estimation with dependent effect sizes: practical considerations including a software tutorial in Stata and SPSS. Research Synthesis Methods. 2013; 5(1):13-30.

57. Egger M, Davey-Smith G. Meta-analysis: Bias in Location and Selection of Studies. British Medical Journal. 1998; 316(7124):61-6. [PubMed: 9451274]

58. Peters JL, Sutton AJ, Jones DR, Abrams KR, Rushton L. Comparison of Two Methods to Detect Publication Bias in Meta-analysis. Journal of the American Medical Association. 2006; 295(6): 676-80. [PubMed: 16467236]

59. Moreno SG, Sutton AJ, Ades AE, Stanley TD, Abrams KR, Peters JL, et al. Assessment of Regression-based Methods to Adjust for Publication Bias through a Comprehensive Study. BMC Medical Research Methodology. 2009; 9(2)

60. Urbanos-Garrido RM, Lopez-Valcarcel BG. The influence of the economic crisis on the association between unemployment and health: an empirical analysis for Spain. European Journal of Health Economics. 2014 Published online in advance of print. 10.1007/s10198-014-0563-y

61. Cordoba-Dona JA, Sebastian MS, Excolar-Pujolar A, Martinez-Faure JE, Gustafsson PE. Economic crisis and suicidal behaviour: the role of unemployment, sex and age in Andalusia, Southern Spain. International Journal for Equity in Health. 2014; 13:55. [PubMed: 25062772]

62. Ouweneel P. Social Security and Well-Being of the Unemployed in 42 Nations. Journal of Happiness Studies. 2002; 3:167-92.

63. Walker L, Mann L. Unemployment, Relative Deprivation, and Social Protest. Personality and Social Psychology Bulletin. 1987; 13(2):275-83.

64. Maki N, Martikainen P. A register-based study on excess suicide mortality among unemployed men and women during different levels of unemployment in Finland. Journal of Epidemiology and Community Health. 2012; 66(4):302-7. [PubMed: 20966447]

65. Ahs AMH, Westerling R. Self-rated health in relation to employment status during periods of high and of low levels of unemployment. European Journal of Public Health. 2006; 16(3):295-305. [PubMed: 16260444] 
66. Strandh M, Novo M, Hammarstrom A. Mental health among the unemployed and the unemployment rate in the municipality. European Journal of Public Health. 2011; 21(6):799-805. [PubMed: 20943994]

67. Zhang J, Yu KF. What's the Relative Risk? A Method of Correcting the Odds Ratio in Cohort Studies of Common Outcomes. Journal of the American Medical Association. 1998; 280:1690-1. [PubMed: 9832001]

\section{Appendix}

\section{Section 1: Full search algorithms for Medline}

1. exp stress, psychological/mo

2. exp Stress, Psychological/

3. exp mortality/

4. mo.fs.

5. (death\$ or mortalit\$ or fatal\$).tw.

6. or $/ 3-5$

7. 2 and 6

8. 1 or 7

9. stress\$.tw.

10. exp caregivers/

11. caregiv\$.tw.

12. (care giver\$ or care giving).tw.

13. exp family/

14. exp siblings/

15. exp divorce/

16. exp marriage/

17. (marital adj (strife or discord)).tw.

18. widow\$.tw.

19. (marriage or married).tw.

20. divorce\$.tw.

21. famil\$.tw.

22. (son or sons).tw.

23. daughter\$.tw.

24. (spous\$ or partner\$ or husband\$ or wife or wives).tw.

25. (mother\$ or father\$ or sibling $\$$ or sister $\$$ or brother $\$$ ).tw. 
26. exp dissent/ and disputes.mp. [mp=title, original title, abstract, name of substance word, subject heading word]

27. exp domestic violence/

28. domestic violence.tw.

29. ((child $\$$ or partner $\$$ or spous $\$$ or elder $\$$ or wife or wives) adj5 (violen $\$$ or abuse $\$$ or beat $\$$ or cruelty or assault $\$$ or batter $\$)$ ).tw.

30. ((mental\$ or physical\$ or verbal or sexual\$) adj2 (violen $\$$ or abuse $\$$ or cruelty)).tw.

31. exp PEDOPHILIA/

32. (pedophil\$ or paedophil\$).tw.

33. exp social class/

34. exp socioeconomic factors/

35. (socioeconomic\$ or socio economic\$).tw.

36. ((financ $\$$ or money or economic) adj (stress $\$$ or problem $\$$ or hardship $\$$ or burden $\$)$ ).tw.

37. exp poverty/

38. (poverty or poor or depriv\$).tw.

39. exp residence characteristics/

40. ((neighbo?rhood or resident\$) adj (characteristic\$ or factor\$)).tw.

41. (crowd $\$$ or overcrowd $\$)$.tw.

42. exp prejudice/

43. (prejudic $\$$ or racis $\$$ or discriminat $\$$ ).tw.

44. exp social isolation/

45. exp social support/

46. (social adj (isolat\$ or support\$ or connect\$ or depriv\$ or function $\$$ or influen $\$$ or interact $\$$ or relationship\$ or separat\$ or ties)).tw.

47. exp friends/

48. (acquaintance $\$$ or companion $\$$ or friend $\$$ ).tw.

49. neighbo?r\$.tw.

50. exp interpersonal relations/

51. (social adj network\$).tw.

52. exp social behavior/

53. (social\$ adj activ\$).tw.

54. $\exp$ work/

Ann Epidemiol. Author manuscript; available in PMC 2016 May 01. 
55. exp employment/

56. exp job satisfaction/

57. exp work schedule/

58. exp occupational disease/

59. exp occupational health/

60. exp workplace/

61. (job or jobs).ti,ab.

62. employ\$.ti,ab.

63. unemploy $\$ . t i, a b$.

64. (shiftwork\$ or (work adj2 shift\$)).ti,ab.

65. karasek $\$ . t i, a b$.

66. overwork $\$ . t i, a b$.

67. ((job or work or employ\$ or occupation $\$$ ) adj (satisf $\$$ or condition $\$$ or discontent or stress\$)).ti,ab.

68. $\exp$ ACCULTURATION/

69. acculturat $\$ . t i, a b$.

70. (migrant $\$$ or immigrant $\$$ or guest work $\$$ ).ti,ab.

71. exp Life Change Events/

72. ((trauma $\$$ or life) adj (change or event\$ or stress $\$)) . t i, a b$.

73. exp natural disasters/

74. (natural disaster $\$$ or earthquake $\$$ or hurricane $\$$ or volcan $\$$ or typhoon $\$$ or tsunami $\$$ or avalanche $\$$ or fire $\$$ or flood $\$$ ).ti,ab.

75. exp FIRES/

76. $\exp$ STRESS DISORDERS, POST-TRAUMATIC/ or exp OXIDATIVE STRESS/ or exp ECHOCARDIOGRAPHY, STRESS/ or exp HEAT STRESS DISORDERS/ or exp DENTAL STRESS ANALYSIS/ or exp STRESS, MECHANICAL/ or exp STRESS FIBERS/ or exp URINARY INCONTINENCE, STRESS/ or exp FRACTURES, STRESS/ or stress disorders, traumatic, acute/ or exp exercise test/

77. ((stress or exercise) adj test $\$)$.sh,tw.

78. exp Accidents, Occupational/

79. (occupation $\$$ adj (hazard $\$$ or accident $\$$ )).tw.

80. or/76-79

81. 2 or 9 

82. or $/ 10-75$
83. or $/ 76-79$
84. 82 not 83
85. and $/ 6,81,84$
86. 8 or 85
87. exp Cohort Studies/
88. Controlled Clinical Trials/
89. controlled clinical trial.pt.
90. ((incidence or concurrent) adj (study or studies)).tw.
91. comparative study.sh.
92. evaluation studies.sh.
93. follow-up studies.sh.
94. prospective studies.sh.
95. control\$.tw.
96. prospectiv $\$ . t w$.
97. volunteer\$.tw.
98. or/87-97
99. 86 and 98
100.limit 99 to humans

\section{Section 2: Coding procedures and variables for which data were sought}

Two authors trained in systematic review coding procedures determined publication eligibility and extracted the data from the articles. Prior to coding, both authors jointly reviewed the titles and abstracts of potential publications to determine whether a given work warranted a full examination for coding purposes. Each of these publications was read independently, with each author forming an opinion on final publication eligibility, assigning a tentative subjective quality rating, and highlighting the data to be coded (see below). The two authors then met in conference to discuss each publication. A study was included if the outcome variable was all-cause mortality, the experience of a stressful life event was measured at the individual level (rather than at the neighborhood level), and a clear comparison was made between a group of people who experienced a particular stressful event and another group who did not. No restrictions were placed on the year a study was published, in what language it was originally written, or the type of outlet in which the paper appeared. Data was entered into a spreadsheet only after agreement had been reached on final publication eligibility, the number of relative risk estimates available for extraction, the values to be assigned for the study design variables (e.g. age range, baseline date) corresponding to each relative risk, and consensus had been established with 
respect to the final subjective quality rating. In some cases, the data entry involved calculating relative risk estimates from raw death rates or from raw count data. For publications reporting multiple analyses of a single sample, data was sought from a statistically-unadjusted model, a model adjusted for age alone, and from the most statistically-adjusted multivariate model. Data were entered on basic spreadsheets (the data spreadsheet being later imported into SPSS for analysis). The variables we sought to obtain from publications were: 1) Author names; 2) author genders; 3) publication date; 4) publication title; 5) place of publication; 6) characteristics of high stress group (e.g. unemployed); 7) characteristics of low stress group (e.g. employed); 8) characteristics shared by both high and low stress groups; 9) percent of the sample that was male; 10) minimum age; 11) maximum age; 12) mean age; 13) ethnicity; name of data source used; 14) geographic location of study sample; 15) baseline start date (day, month, year); 16) baseline end date (day, month, year); 17) follow-up end date (day month, year); 18) maximum follow-up duration; 19) average follow-up duration; 20) information on timing of stress relative to baseline start date; 21) information on the structure of the follow-up period (e.g. were there any gaps between the end of baseline and the beginning of follow-up?); 22) statistical technique used; 23) total number of persons analyzed in the publication; 24) total number of persons analyzed for the specific effect size; 25) number of persons in the high stress group; 26) number of deaths in the high stress group; 27) number of persons in the low stress group; 28) number of deaths in the low stress group; 29) death rate in the high stress group; 30) death rate in the low stress group; 31) effect size; 32) confidence interval; 33) standard error; 34) t-statistic; 35) Chi-square statistic; 36) minimum value for $\mathrm{p}$-value; 37) maximum value for p-value; 38 ) full list of control variables used; 39) date of data extraction; 40) subjective quality rating; 41) number of citations received by publication according to Web of Science; 42) number of citations received according to Google Scholar; 43) 5-year impact factor for place of publication.

\section{Section 3: Additional information on the conversion of odds ratios and relative risks to hazard ratios}

All non-hazard-ratio point estimates were converted to hazard ratios (the most frequently reported type) using one or both of the following equations [67]: $\mathrm{RR}=\frac{\mathrm{OR}}{(1-r)+(r * \mathrm{OR})}$ and $\mathrm{HR}=\frac{\ln (1-\mathrm{RR} * r)}{\ln (1-r)}$, where $\mathrm{RR}$ is the relative risk, $\mathrm{OR}$ is the odds ratio, $\mathrm{HR}$ is the hazard ratio, and $r$ is the death rate for the reference (i.e. employed) group. 


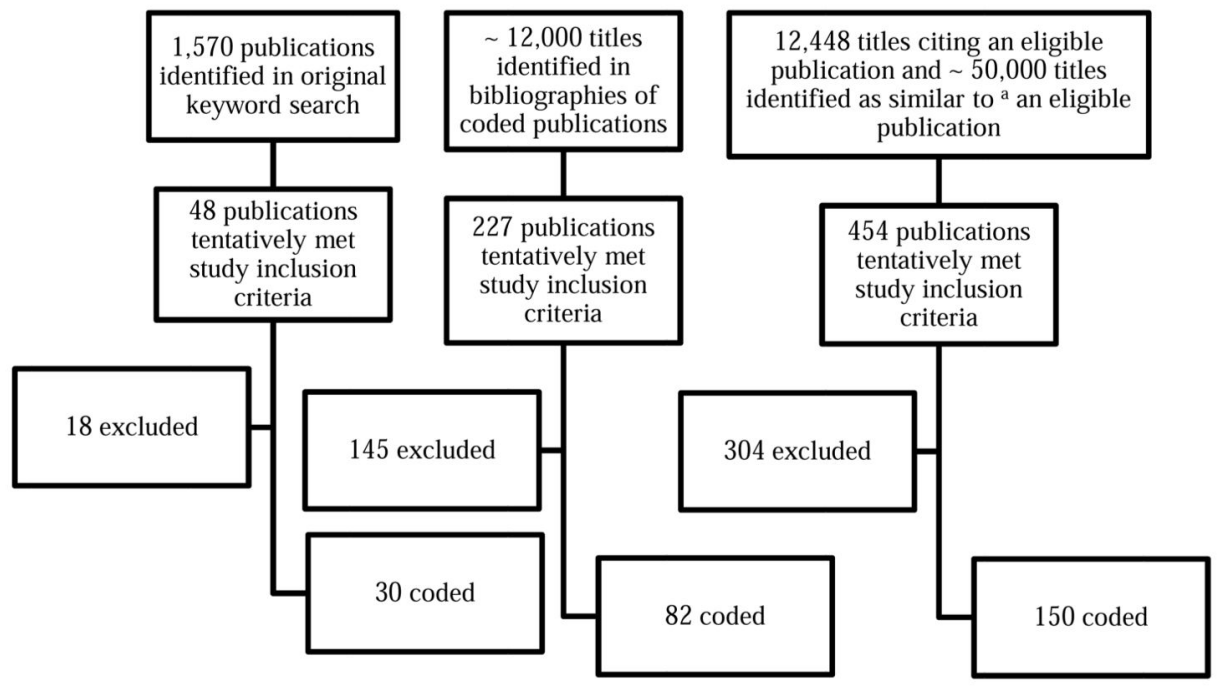

Total pool of 262 publications for meta-analyses of stressful life events and all-cause mortality

220 publications containing stress measures other than unemployment

publications containing an

insufficient age range or duplicate findings

42 publications containing data on unemployment and all-cause mortality

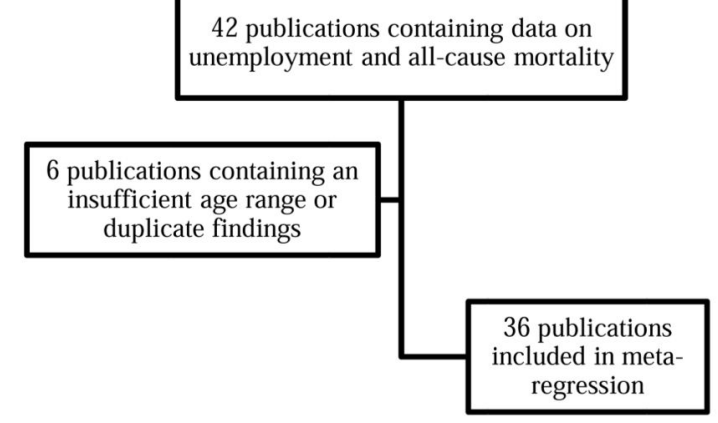

Figure 1. Flow diagram for literature search

"Here, "similar to" refers to the definitions for article similarity used by Google Scholar and ISI Web of Science 


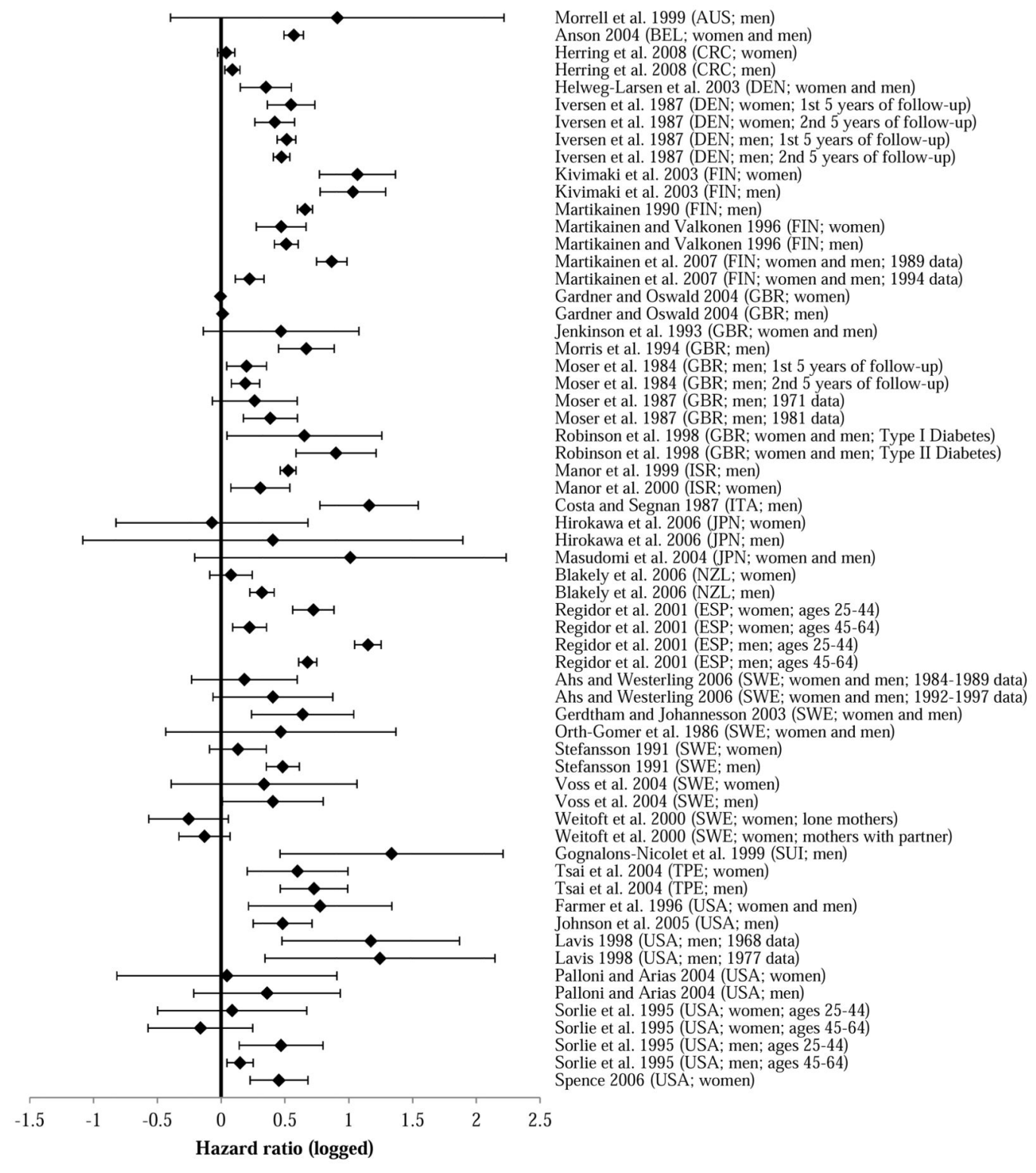

Figure 2. Forest plot of the $62 \mathrm{log}$ hazard ratios (unemployed vs. employed) included in analysis, sorted by nation $^{\mathrm{a}}$

${ }^{\mathrm{a}} \mathrm{AUS}=$ Australia; BEL=Belgium; $\mathrm{CRC}=$ Costa Rica; DEN=Denmark; ESP=Spain;

FIN=Finland; GBR=United Kingdom; ISR=Israel; ITA=Italy; JPA=Japan; NZL=New

Zealand; SWE=Sweden; SUI=Switzerland; TPE=Taiwan (Taipei); USA=United States 


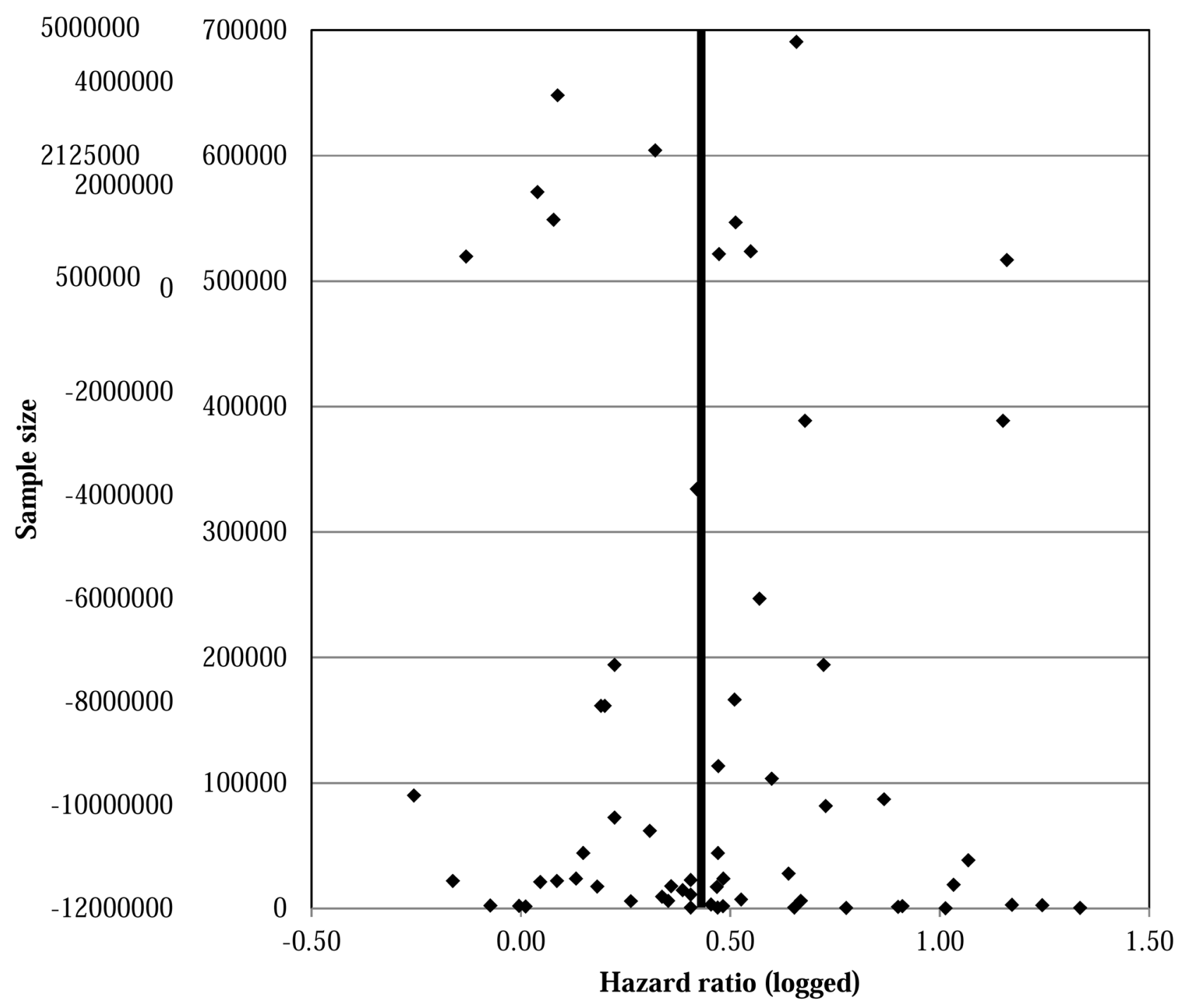

Figure 3. Funnel plot of 62 hazard ratios (logged) included in analysis vs. sample size ${ }^{\mathrm{a}}$ a Vertical line denotes the mean log hazard ratio of 0.43 . To better show the dispersion of points, the y-axis scale is less condensed from 0 to 500000 and more condensed from 500 000 to 5000000 . 

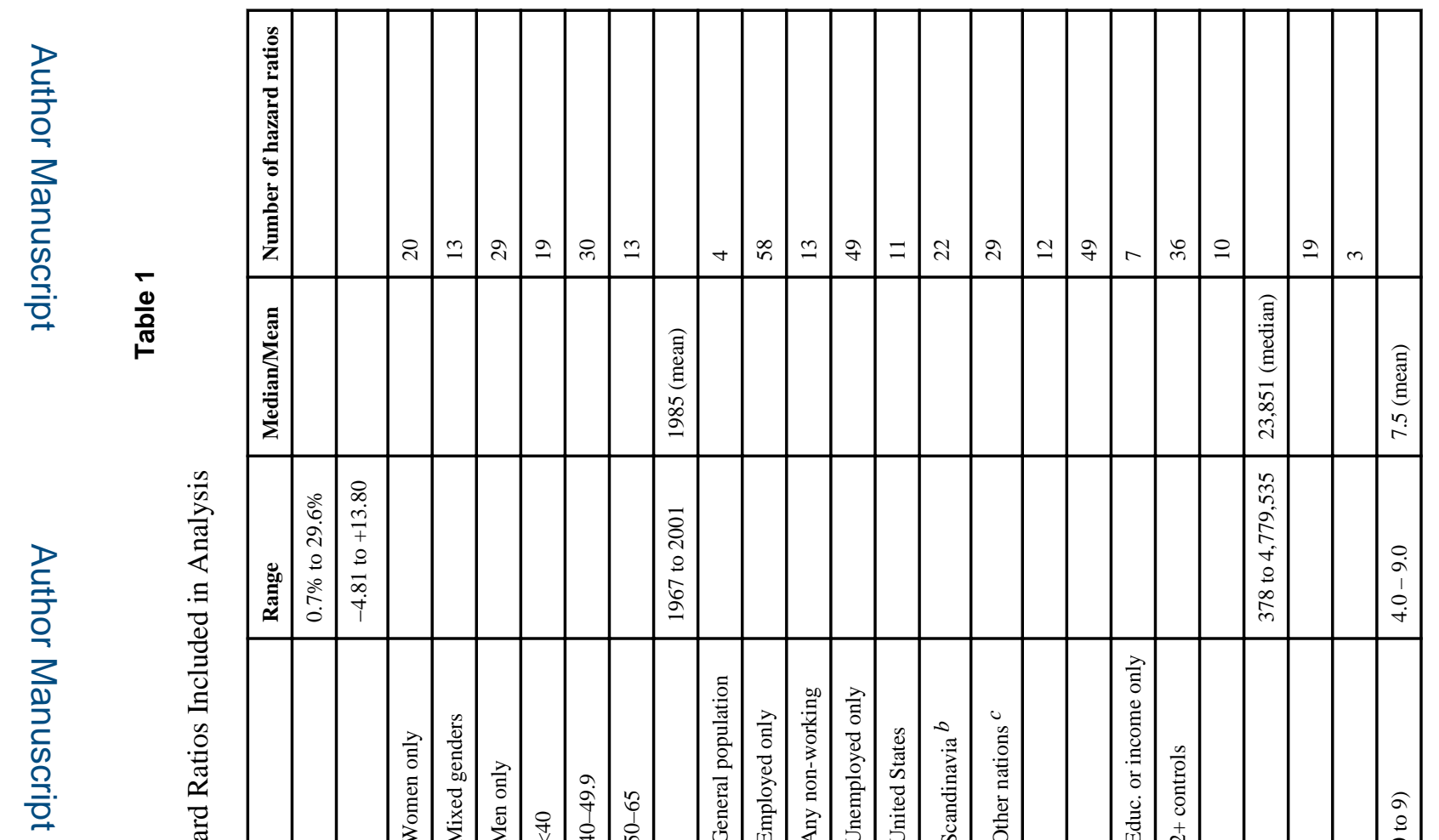

D্
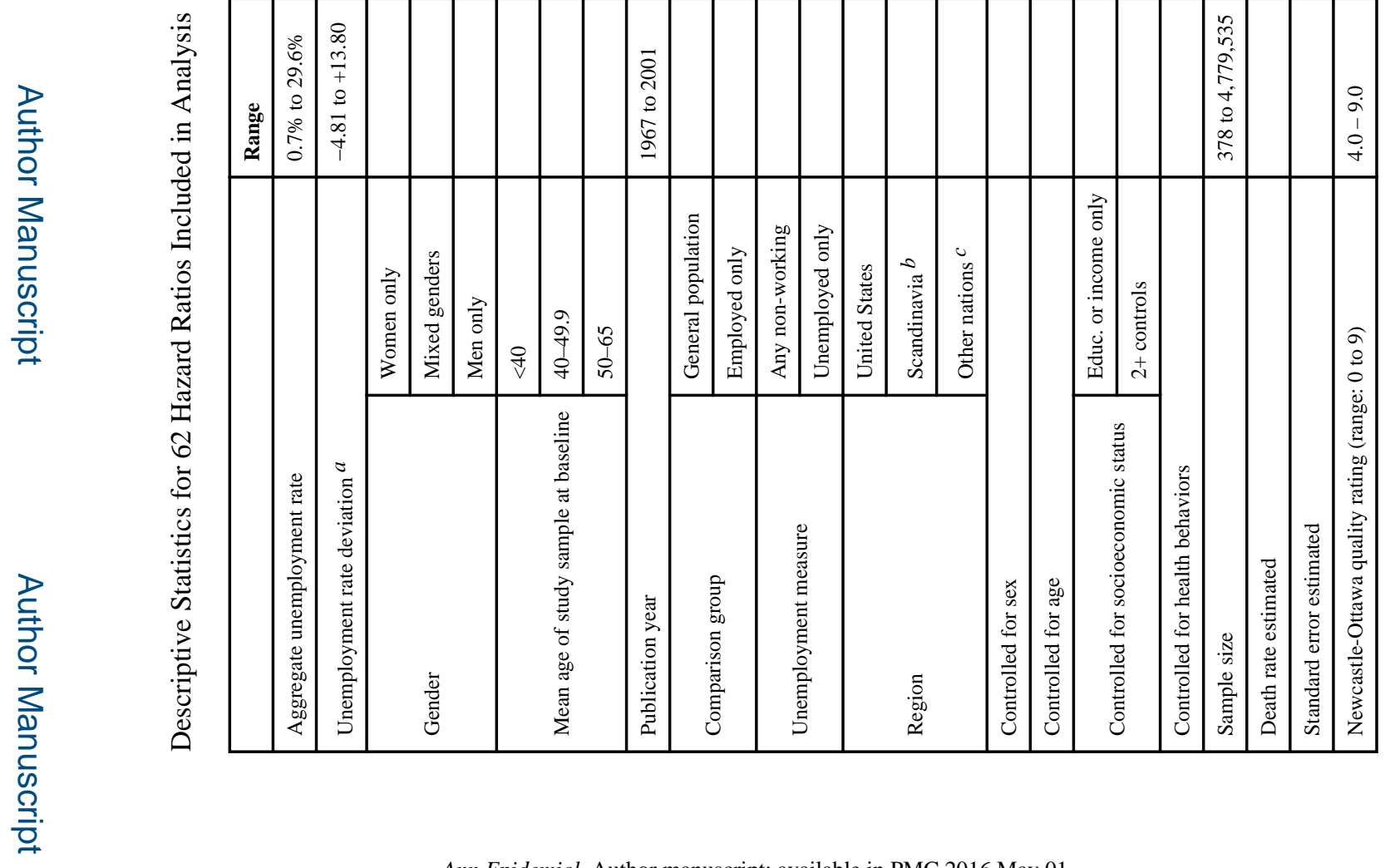

Ann Epidemiol. Author manuscript; available in PMC 2016 May 01 


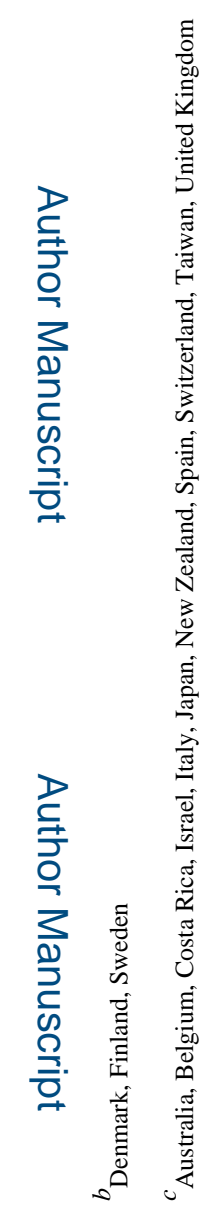

로을

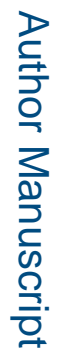

Ann Epidemiol. Author manuscript; available in PMC 2016 May 01. 

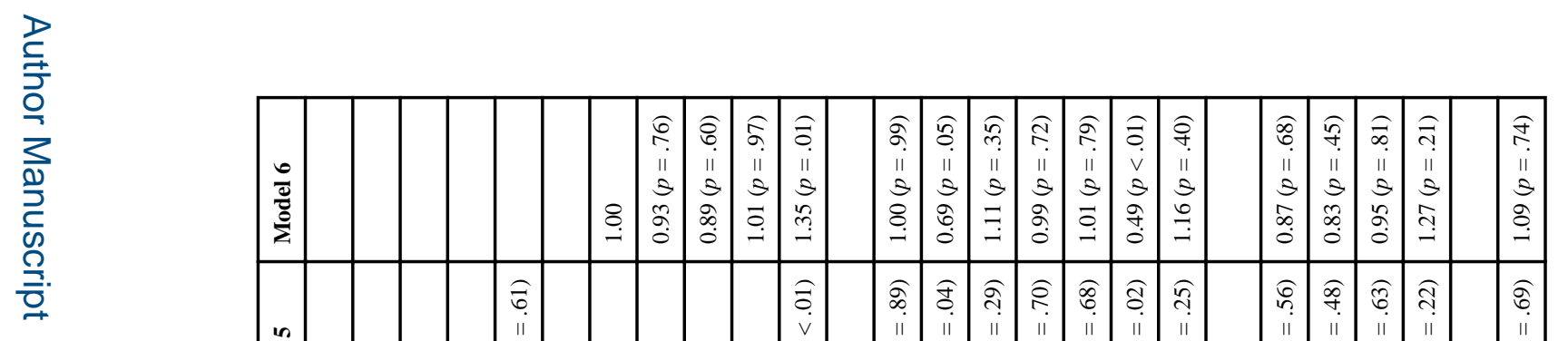

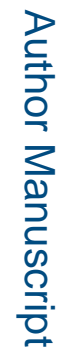

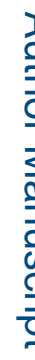
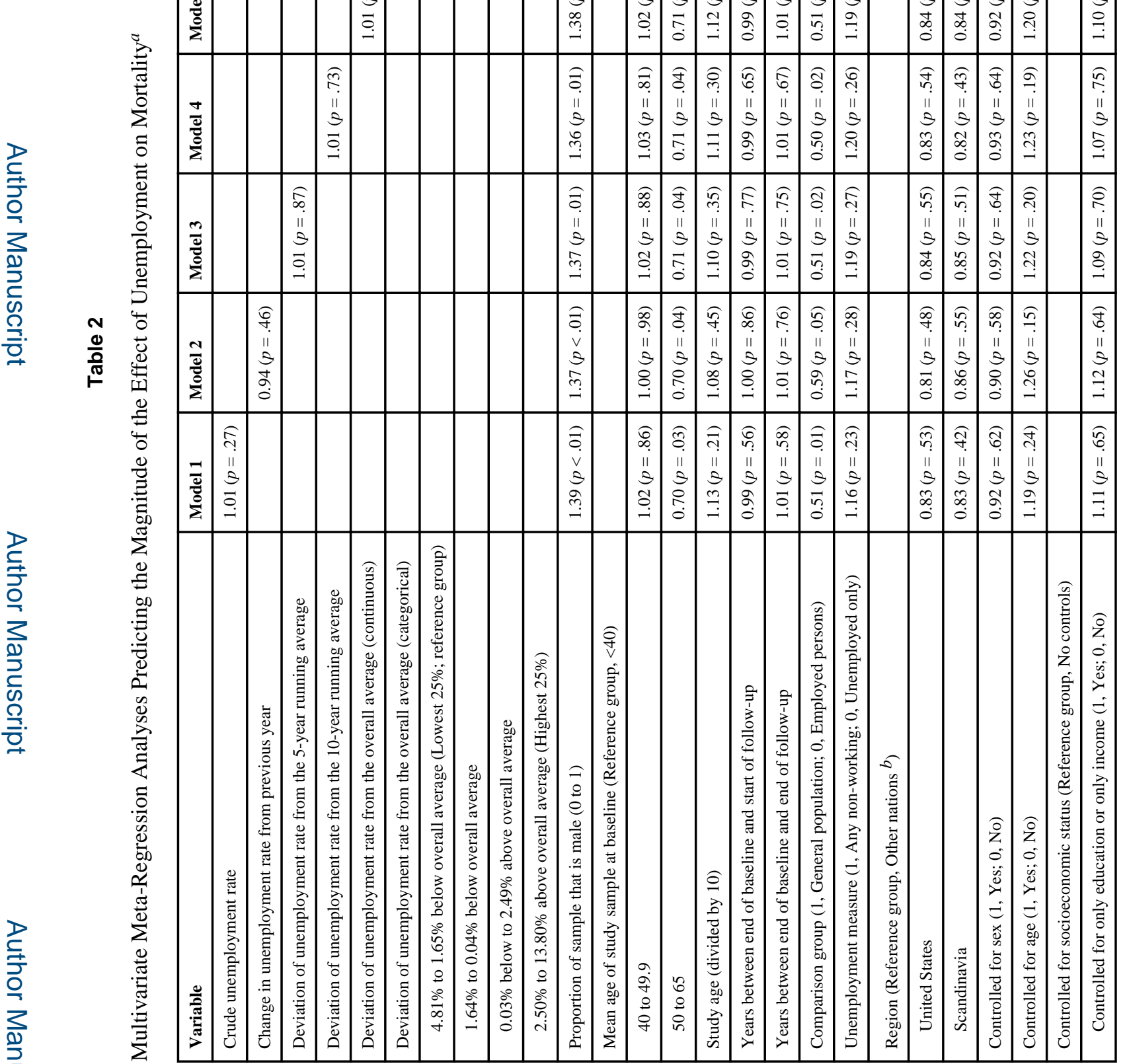

Ann Epidemiol. Author manuscript; available in PMC 2016 May 01. 


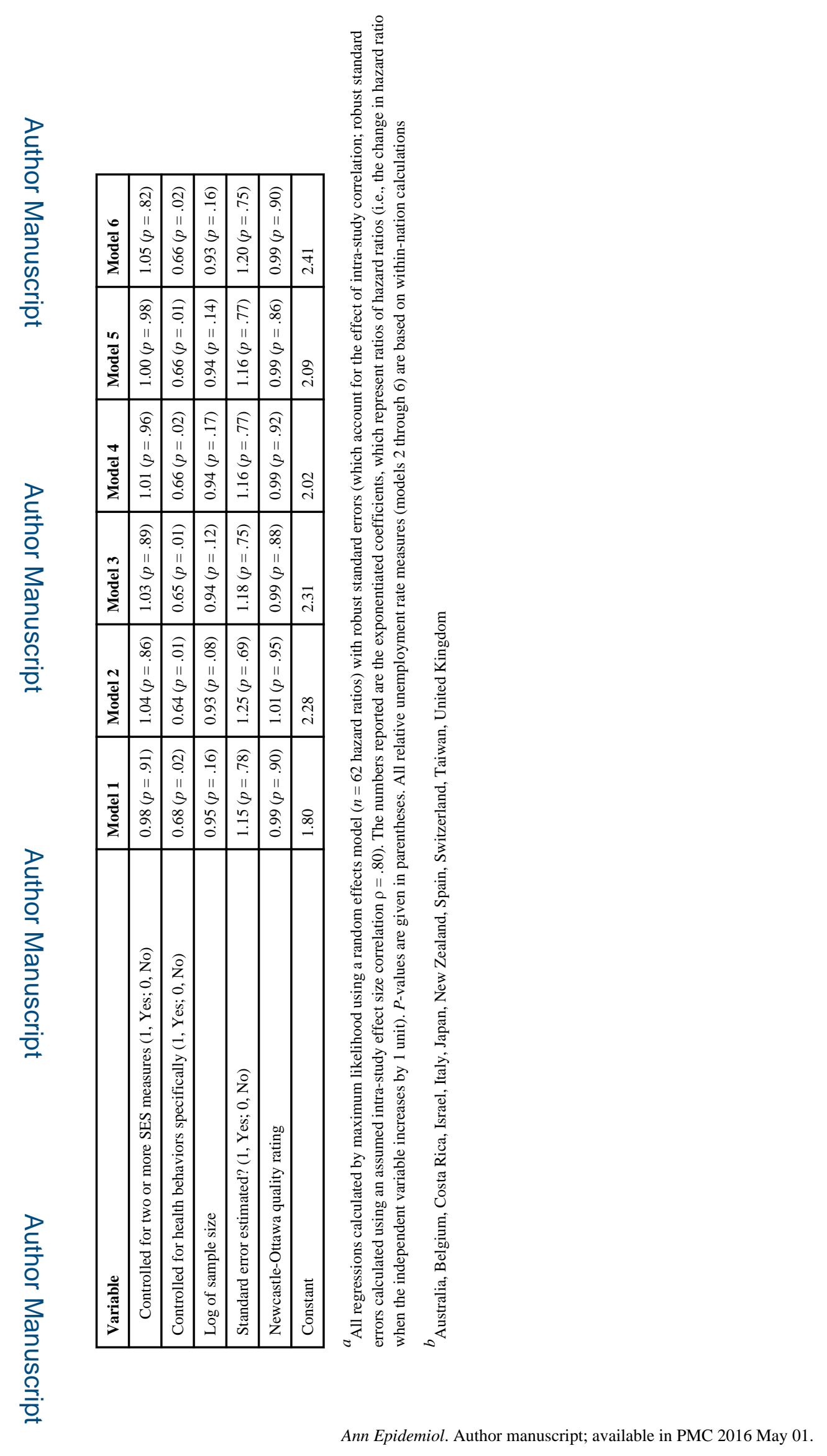

